\title{
Thyroid Gland Angiosarcoma
}

National Cancer Institute

\section{Source}

National Cancer Institute. Thyroid Gland Angiosarcoma. NCI Thesaurus. Code C6043.

A usually aggressive malignant vascular tumor primarily involving the thyroid gland. It is often associated with longstanding nodular goiter. 